\title{
The Experience of Watching Dance:
}

\section{Phenomenological - Neuroscience Duets}

\begin{abstract}
$\underline{\text { ABSTRACT }}$
This paper discusses possible correspondences between neuroscientific findings and phenomenologically informed methodologies in the investigation of kinesthetic empathy in watching dance. Interest in phenomenology has recently increased in dance studies (e.g. Rothfield 2005, Legrand \& Ravn, 2009) and cognitive neuroscience (Gallagher $\&$ Zahavi, 2008). The correlation of subjects' neurophysiological data with qualitative responses has been commonly accepted as a means of researching the human brain in the study of visual perception (Spillmann, 2009) and recently in the study of consciousness (Gallagher \& Zahavi, 2008), with similar issues in clinical psychology (Mishara, 2007) and biology (Kosslyn et al., 2007). Yet the relationship between neuroscience and qualitative research informed by phenomenology remains controversial. How qualitative research handles subjective experiences is somewhat incompatible with common statistical analysis of objective data. Recent technological developments in cognitive neuroscience have inspired a number of researchers to use more naturalistic stimuli, out of the laboratory environment, such as dance, thereby perhaps helping to open up the cognitive sciences to more phenomenologically informed approaches. A question central to our research, addressed here, is how the phenomenal experiences of a dance audience member, as accessed by qualitative research methods, can be related to underlying neurophysiological events. We outline below some methodological challenges encountered in relating audiences' first-person experiences watching live dance performance to third-person neurophysiological evidence of the audiences' experiences.
\end{abstract}




\section{Cognitive Neuroscience, Phenomenology and Dance: Questions of Approach (Introduction)}

\section{Shared interest in dance}

A revival of interest in phenomenological analysis of dance (e.g. Rothfield 2005; Legrand \& Ravn, 2009) has coincided, in the last decade, with the increased presence of dance in neuroscientific research. Most neuroscientific studies used dancers as experts (Jola \& Mast, 2005a) and/or dances as stimuli (e.g. Brown, Martinez, \& Parsons, 2006; Calvo-Merino, Glaser, Grèzes, Passingham, \& Haggard, 2005; Calvo-Merino, Grèzes, Glaser, Passingham, \& Haggard, 2006; Cross, Hamilton, \& Grafton, 2006; Jola, \& Mast, 2005b; MacFarlane, Kulka, \& Pollick, 2004) primarily to investigate processes involved in movement execution and observation. Generally, studies with a more phenomenological approach emphasise the first-person 'lived' experience of phenomena, such as the experience of what it is like to be a dance spectator, while those with a neuroscientific approach have a more third-person objective perspective such as trying to find out what processes implicitly occur in the brain when a person watches dance. In the literature to date related to investigating dance spectatorship, phenomenology and neuroscience have primarily remained distinct rather than complementary.

In the present paper we discuss research processes and methods used to try to bridge the perceived gap between these two approaches in an interdisciplinary collaborative project. As neuroscientists and audience researchers informed by phenomenological approaches, we are aiming to understand the relationship between the first-person experiences of audience members and the corresponding neurophysiological data. Due to the complexity of the stimuli and the diversity of the audiences' experiences, we cannot simply match the knowledge of elementary neural processes in visual perception to the experience of an audience member watching a dance performance in the theatre. ${ }^{1}$ How could we, for example, explain the very individual responses to one performance? A recently published essay by the father of

\footnotetext{
${ }^{1}$ Theatre dance refers to dance as an art form, rather than social dance (and here it should be noted that the viewing conditions we are talking about are those of Western theatre dance).
} 
psychophysics, Gustav Fechner (2009), using introspection provides some insight into the intrinsic difficulty in matching experience to psychological processes.

Our research specifically explores audiences' responses to live theatre dance using methods drawn from cognitive neuroscience and qualitative audience research informed by phenomenology. We argue that while these fields carve out different and sometimes incommensurable areas of knowledge, it is possible to open up channels of communication between them, which can enrich our overall understanding of spectators' responses to this significant art form, which is currently enjoying a high profile on the UK cultural scene. Styles of dance we refer to in this paper are bharatanatyam, which is a classical form of indian dance, contemporary, and ballet.

The neuroscientific focus on dance has been strongly motivated by a surge of research outputs related to the identification of the so-called mirror neurons (Gallese, Fadiga, Fogassi, \& Rozzolatti, 1996). These neurons in the frontal and parietal cortices of monkey brain fire both when a monkey grasps for food as well as when the monkey simply observes the experimenter executing the same grasping action. In the search for understanding the functional properties of equivalent neurons in the human brain, dance has proven to be a useful tool. Dance enables neuroscience to study basic functional properties of movement observation which include non-verbal communication and aesthetic appreciation different to many goal and object-related 'everyday actions', such as grabbing a cup, and sporting activities. It may be that in some ways spectators' responses to dance, in particular motor simulation, are similar to those when watching other physical activities like gymnastics (Munzert, Zentgraf, Stark, \& Vaitl, 2008) or basketball (Aglioti, Cesari, Romani, \& Urgesi., 2008). However, theatre dance combines physical (athletic) components with artistic (aesthetic) values. Unlike competitive sports, gymnastics or athletics, or even competitive dance (such as ballroom competitions), the quality of theatre dance cannot be measured in terms of a 'score' by which one beats an opponent (see also Friesen, 1975). A theatre dance performance is a multifunctional socio-cultural event constituted of many diverse strands, including the dancers, the music that accompanies the movements, the costumes, the lighting, the set, the other audience members, and so on, that work together to impact on the spectator in the moment of watching. 
Certain attributes of theatre dance, such as the interaction of several modalities like music and movement and also the long duration of dance performances (in contrast to the 3 seconds presentation duration of stimuli commonly used in neuroscientific experiments), make its use in such experiments problematic. Qualitative methods of audience research, informed by phenomenology, are well placed to address some issues which can be challenging for a neuroscientific approach. For instance, qualitative audience research emphasises describing experience in an exploratory, interactive process which takes place after, rather than during the event and itself contributes to uncovering and shaping spectators' experience. Moreover, unlike neuroscience, there is no clear-cut distinction between collecting and analysing data, as the methods (e.g. the questions asked in interviews) are already in themselves part of the analysis. This means that each process is unrepeatable and aims to be valid on its own terms rather than to provide a predictive model. However, audience research does not have access to the brain functions studied by neuroscience. We feel that neither qualitative research nor neuroscience can present a complete picture of spectator response and we are interested in combining both first-person experiences and third-person neurophysiological data to explore spectators' kinesthetic responses to watching dance.

\section{The collaborative research project}

The work presented here comes out of a collaborative research project called "Watching Dance: Kinesthetic Empathy", funded in the UK by the Arts and Humanities Research Council. The project uses audience research and neuroscience to explore how dance spectators respond to and identify with dance based upon the assumption of the concept of kinesthetic empathy. The following essay addresses some questions emerging from descriptive data gathered in qualitative interviews with audience members and from data produced by questionnaires and by fMRI (functional magnetic resonance) and TMS (transcranial magnetic stimulation, see section 2 for further methodological details), which were analysed quantitatively. The crucial question for us is to what extent (if at all) do spectators of dance feel that they are participating in the movement of the dancer(s)? And in terms of the methods employed to answer this question, how might spectators' experiences as reported through qualitative audience research correspond to neurophysiological data as 
derived through fMRI and TMS? And in particular, what can we learn from combining these approaches that we could not discover by either method used separately?

In the present paper, our main aim is to argue for the importance of interdisciplinary collaboration, rather than to engage with the concept of kinesthetic empathy itself and the debates surrounding it. However, a brief overview of this topic will be useful at this juncture. In dance research, the concept of kinesthetic empathy has emerged to describe the response of some spectators when watching dance. Spectators frequently report that even while sitting still, they feel they are participating in the dance they observe, experiencing movement sensations and related feelings and ideas. This type of response has been described in terms of kinesthesia (Daly, 1992) and kinesthetic empathy (Hagendoorn, 2004; Lipps, 1906; Martin, 1939), and is a major focus of our collaborative research. The concept of kinesthetic empathy as it has been discussed in dance studies is controversial, both in terms of how it is defined and how it has been regarded by scholars and critics. ${ }^{2}$ For some, it is integral to the experience of the ideal dance spectator, while others see it as falsely universalist (see discussion in Reason \& Reynolds 2010). However, it is currently under the spotlight, partly as a result of the impetus provided by neuroscience research on 'mirror neurons', as mentioned above.

Some neuroscience researchers claim that there are brain areas in action observation linked with empathic responses (Keysers \& Gazzola, 2009). Empathy has been described as "the drive or ability to attribute mental states to another person/animal, and entails an appropriate affective response in the observer to the other person's mental state" (Baron-Cohen \& Wheelwright, 2004). Some researchers focus on the affective rather than the cognitive aspects of empathy and acknowledge any form of affective response as empathic, whether matching the experience of another or showing compassion for another, or simply any type of response (e.g. pleasure at somebody else's pain). Definitions of kinesthesia and proprioception have

\footnotetext{
${ }^{2}$ See for instance Foster, S. (2008). Movement's Contagion: The Kinesthetic Impact of Performance. In Davis, Tracy C. (Ed) The Cambridge Companion to Performance Studies (pp. 46 - 59). Cambridge: Cambridge University Press; Järvinnen, H. (2007). Some Steps Towards a Historical Epistemology of Corporeality. Society of Dance History Scholars, 30th Annual Conference Co-sponsored with CORD, Centre National de la Danse, Paris; McFee, G. (1992). Understanding Dance. London: Routledge.
} 
a complex history (see Foster, 2008), but at least since Sherrington's work on the 'muscular sense' (Sherrington, 1907), proprioception (or kinaesthesia) is widely accepted in modern cognitive psychology as a distinct multicomponent sensory modality, often referred to as the sixth sense (Wade, 2003). ${ }^{3}$ Many studies of proprioception and kinaesthesia involve angle or position matching, or balance tests. The role of motor simulation in affective empathy is, however, novel.

Neurophysiological approaches have the advantage of measurement at the moment of the activity of watching dance. However, the popular neuroimaging techniques which enable study of the functional role of cortical areas have spatial and temporal restrictions which make it impossible to expose participants to real life dance events. Therefore, even if one agrees with Zeki (2002) in theory, that there is a neurobiological network responsible for the spectator's response, in practice, we may not be able to explain it at this point in time by the use of a single methodological approach. As mentioned above, dance is more than complex abstract movement sequences of three seconds in front of a blue background, as it can be found in neuroscience studies. In our research, we wanted to try to maintain the variables of performance, such as costume, music, and longer duration.

The diversity of dance theatre aesthetics and the wide range of subjective preferences prompted us to study individual differences in spectators' experience when watching dance and to explore links with their neuronal activity. For instance, in our first study, we measured how the visual experience of watching dance affects different dance spectators' verbal and neurophysiological responses to watching their preferred, familiar style as compared to a novel, unfamiliar style of dance. In brief, we found evidence that motor simulation, which we relate to kinesthetic experience, is

\footnotetext{
${ }^{3}$ Proprioception and kinesthesia are often used interchangeably but proprioception is used more specifically to describe static limb position sense while kinesthesia is used more generally to refer to the sensation of movement of ones own body. The sensory experiences of position and movement derive from signals from several classes of receptors, including those in the muscles, joints, and skin (Proske, U., \& Gnadevia, S. C. (2009). The kinaesthetic senses. Journal of Physiology, 587(Pt 17), 4139 - 4146). How information from different receptors is integrated in the human brain to a coherent multisensory experience is still an open question. Together with other sensory modalities, in particular vision, proprioception has become a useful way to investigate how the body might be mentally represented (Graziano, M. S. A. \& Botvinick, M. M. (2002). How the brain represents the body: insights from neurophysiology and psychology. In W. Prinz and B. Hommel (Eds) Common Mechanisms in Perception and Action: Attention and Performance XIX (pp. 136 - 157). Oxford: University Press).
} 
modified by both visual expertise and by the spectators' empathic abilities. However, the link between motor simulation and empathic responses remains hypothetical. The simultaneous occurrence in some individuals of kinesthetic sensation and motor simulation is the only evidence of their relatedness. Similarly, we cannot yet conclude whether enhanced empathic abilities led to enhanced empathic responses.

"Watching Dance: Kinesthetic Empathy" thus faces at least two methodological challenges. First, investigating dance in its original forms represents a difficulty for conventional neuroscience research in particular due to time constraints (dance lasts much longer than conventional experimental stimuli) and less rigorously controlled stimuli (dance is multilayered). Second, linking spectators' experiences with their neuronal underpinnings challenges audience research to generalise across individual experiences in order to make the findings comparable with neuroscientific results.

\section{Dance turns science round and round}

\section{Why research on watching dance differs from existing neuroscience research on visual motion perception}

In visual perception research, how neuronal processes give rise to a unified experiential perception of objects or events has been investigated for over half a century (Spillmann, 2009). In particular, scientists have found neurophysiological mechanisms that are indispensable in the explanation of such visual percepts. Quite a large number of these are related to the ways in which we perceive motion visually, such as grouping by coherent motion ${ }^{4}$, apparent motion ${ }^{5}$, or our extraordinary ability

\footnotetext{
${ }^{4}$ The perception of a coherent motion can be the result of a combination of several different motion vectors. For example, when two grating patterns that shift into different directions are superimposed onto each other, the resulting percept can be that of one coherent moving plaid pattern (see Adelson, E. H., \& Movshon, J. A. (1982). Phenomenal coherence of moving visual patterns. Nature, 300(5892), $523-525)$.

${ }^{5}$ Apparent motion describes the phenomenon of perceiving motion when there is none. For instance, when a stationary object is presented first in one position, and then, after a short black out another identical object is shown at another location instead, the observer has the impression of seeing one single object move from one place to the other instead of two alternately presented objects, as first described in Exner, S. (1875). Experimentelle Untersuchungen der einfachsten psychischen Processe: IV. Abhandlung, Die Empfindungszonen des Sehnervenapparats. Archiv für die gesamte Physiologie des Menschen und der Tiere, 11, 581 - 602.
} 
in biological motion perception ${ }^{6}$. For example, grouping of coherent motion has been described as the most powerful example of a correlation between neurophysiological findings and perceptual experience (Spillmann, 1999, p. 1479). An example of such grouping is when a circle of regularly spaced dots within a field of random dots can be perceived in the instant they start moving coherently. This so-called pop-out effect has been explained by selective neuronal activity for coherent motion in the visual areas (V1 and MT) of the monkey's brain (for details see Spillmann, 2009). Also, some scientists were working bi-directionally, which means that they were not just studying neural correlates of perceptual illusions, but they also created perceptual illusions based on their understanding of perceptual mechanisms. This is a rare approach; but if successful, it allows an experiential way of evaluating scientific models of perception. ${ }^{7}$ Hence, in visual perception research, the descriptions of the experiences of perceptual illusions and the neurophysiological data gathered during the perceptual processes have been successfully complementing each other. ${ }^{8}$ However, several factors distinguish this type of research from studying audiences' experience of watching dance.

\footnotetext{
${ }^{6}$ Any form of perceived motion derived from human or animal movements can be described as biological motion. The term is mostly used, however, to describe a unique form of presentation, by a handful of moving dots only (see Figure 1). Interesting about the perception of biological motion is that human observers are particularly sensitive to its spatio-temporal parameters (see Johansson, G. (1973). Visual perception of biological motion and a model for its analysis. Perceptions \& Psychophysics, 14, $201-211)$.

${ }^{7}$ See examples of created illusions on http://www.neuralcorrelate.com/

${ }^{8} \mathrm{~A}$ similar approach can be seen in choreography: the question is sometimes posed as to whether neuroscience findings could contribute to choreographic decision making. One way to link neuroscientific findings with productive creation can be found in Hagendoorn, I. (2010, forthcoming). Dance, choreography and the brain. In D. Melcher \& F. Bacci (Eds.), Art and the senses. Oxford: Oxford University Press). By the use of an imaginary choreography, the author considers where cognitive neuroscience can be linked with the elements of a dance work. This knowledge could be used by dance spectators to reflect on their own responses as well as by choreographers and dancers to understand how artistic decisions might affect the spectators' responses. Also, attempts have been made to create dance works based on neuroscientific findings or experimental approaches (Hansen, P., \& Barton, B. (2009). Research-Based Practice Situating Vertical City between Artistic Development and Applied Cognitive Science. TDR: The Drama Review, 53(4), 120 - 136; see also Jola, C. (2010). Research and choreography. Merging dance and neuroscience. In B. Bläsing, M. Puttke \& T. Schacke (Eds.), The neurocognition of dance. Mind, movement, and motor skills. (pp. 203-233). London: Psychology Press). However, this is a very complex issue. To date, we don't know enough about the multitude of sensory interactions that lead to the audiences' experience when watching dance which could then be used for choreographic practice. There are clearly enormous differences between choreographing a dance work and creating perceptual illusions for scientific study. We may be able post-hoc to infer the contribution of perceptual properties to effects of artistic work (Melcher, D., \& Bacci, F. (2008). The visual system as a constraint on the survival and success of specific artworks. Spatial Vision, 21(3-5), 347-362); but (un-)fortunately, it is not simple to use modern neuroscientific methods for artistic creation (for an example, Goebel, R. (2008). Response to Karaszewski: creating significant art products requires the brains of artists. Trends in Cognitive Sciences, 12(5), 171-172).
} 
In visual perception research, the approach is confined to the study of mostly low-level visual perceptual mechanisms (which means early in the process of visual perception) whereas watching dance ultimately involves higher-level processes. Also, in contrast to the diverse complex strands we have referred to in the context of watching dance, the engagement with the stimuli in low-level research in perception is often limited to visual aspects of percepts in the form of a perceptual illusion which is perceived consistently across many participants. Finally, the stimuli used to study visual perception are predominantly controlled with precise millisecond timing, and retraceable to an experimentally controlled event. A good example is the immediate response of a neuron in the visual cortex to a light being switched on-and-off as shown by Jung et al. (see Spillmann, 1999, p. 1462). Watching dance, however, is not based on a single clear indicative event such as switching on-and-off of sensory stimulation. Dance is multimodal and ephemeral, and as if that is not enough, not every performance can be the same, also limiting reproducibility.

Due to the complexity of the stimuli and the diversity of the audiences' experiences, we cannot simply match the knowledge of elementary neural processes in visual perception to the experience of an audience member watching a dance performance in the theatre. While visual and notably auditory information are the main sensory stimulations the spectator is engaged with, what is interesting about dance (and other art forms) is that they bring together experiences on different levels, e.g. perceptual, emotional, and cognitive. Research in visual perception rarely connects the visual phenomena with diverse levels of individual experience and generally uses reduced stimuli with short presentation times that do not allow individual processes based on extended time exposure to kick in (Hasson, Yang, Vallines, Heeger, \& Rubin, 2008). Hence, any researcher seriously investigating audiences' engagement in watching dance has to deal with manifold phenomenological descriptions or neuronal/behavioural responses.

\section{The evolution of 'naturalistic' stimuli in cognitive neuroscience}

The experimental setup classically used in cognitive neuroscience consists of manipulating a couple of features of a particular predominantly visual or auditory stimulus, in order to identify the effect of one feature upon another with a certain 
statistical significance and power. This approach has provided much scientific insight into many areas, beyond human perception. However, the inferences made from such highly controlled approaches are not necessarily transferrable to complex situations. In other words, the 'artificial' experiments have little in common with the 'real world'. We have outlined some of the issues below.

There has been previous criticism in scientific fields of studies whose models were based on reductionist approaches (e.g. Dehaene, 1989). An example of change of stimulus complexity in experimental research is illustrated in Figure 1. Graphical displays with a number of simplified objects or letters as illustrated in the upper row of Figure 1 were frequently used by experimental psychologists to test their models of perception and attention. Treisman and Gelade (1980), for example, verified their feature-integration theory (i.e. complex visual scenes are perceived via single features which are then combined in a second step) against the Gestalt account (i.e. a complex visual scene is perceive as a whole or 'gestalt' which can then be dissected into its components) by means of similar stimuli. Also, the study of biological motion perception mostly involves short movement sequences. These are often presented in the form of point light displays, as shown in the middle row of Figure 1, in order to remove any visual information that may interfere with the research question or just add noise to the data (Pollick, Jola, Petrini, McKay, McAleer, \& Simmons, 2010). However, the visual scene a dance spectator is exposed to is hardly ever that simple. An audience member may - from a good seat - see several dancers, involved in different actions, playing particular characters as shown at the bottom of Figure 1, all of which are part of the experience of watching dance. And importantly, the inferences made from highly controlled approaches as exemplified above are not necessarily transferrable to complex situations. In particular, recent studies showed that the complexity of experimental stimuli does affect visual and auditory perception (Cook \& Van Valkenburg, 2009).

As one might expect, in the vast majority of published studies that used 'dance' to investigate neurophysiological processes, the movement sequences have not yet reached the full potential required to study the multiple levels involved when watching theatre dance. The stimuli used in empirical neuroscientific studies differ from stimuli experienced outside the lab environment on several levels. For one, 
simple, constrained stimuli have an artificially reduced number of factors. A reasonable number of studies investigating human motion do present a movie of the full human body in motion but control for factors such as face recognition by blurring the face of the performer (e.g., Calvo-Merino et al., 2006). Also, in most neuroscientific studies, the combinations of features are limited. For example, movements presented in controlled studies are using neutral background and neutral clothing to control for possible confounds. To reduce confounding variables, usually no music is played with the dance movements in experimental studies. However, in 'real-life', dance frequently plays with sound effects. Finally, the time is constrained, ranging from presentations in the millisecond range in vision perception research to a few seconds in neuroscientific studies on motor control.

We recognise that these previous studies were important to the development of dance and neuroscience collaborations and using simplified stimuli is still an accepted way to study human cognitive and emotional processes. After half a century of increasingly proficient reductionist approaches, however, a number of cognitive neuroscientists are eager to develop methods that allow experimental investigation by means of so-called 'natural' stimuli (Hasson, Nir, Levy, Fuhrmann, \& Malach, 2004; Wade \& Bruce, 2001).

insert Figure 1 about here

\section{Complex data in qualitative research}

For our purposes, the research has to engage with dance as a Western theatre art form, i.e. unconstrained by laboratory conditions and presented as an art form to theatre-going spectators, thereby raising questions of aesthetics (e.g. judgment/taste, pleasure). If studying complex, unpredictable data presents difficulties for neuroscience, this is precisely the forte of qualitative research methodologies. Qualitative research is concerned with the various ways in which the social world is 'interpreted, understood, experienced, produced or constituted' (Mason 2002a, p. 3). It emerges from different traditions and disciplines in the human and social sciences and encompasses a variety of methods related to divergent disciplinary approaches and philosophies. The main methods associated with qualitative research are 
ethnography/participant observation; qualitative interviewing; focus groups; language-based approaches (such as discourse analysis); collection and analysis of documents and texts, and visual methods. Within this methodological variety there are common strands which distinguish qualitative research from perspectives commonly associated with cognitive sciences. Most obviously, a large amount of research in the cognitive sciences is 'quantitative', with outcomes which can be expressed numerically. Qualitative researchers, by contrast, maximize the depth, complexity and nuance provided by the data. Although it may involve some quantification, this is not regarded as central. Importantly, audience research is concerned that meaning would be lost if data were reduced to numbers. In qualitative research there is a two-way relationship between researcher and data where the researcher aims to learn from the data.

'All qualitative methods seek to discover understanding or to achieve explanation from the data instead of from (or in addition to) prior knowledge or theory. Thus the goals always include learning from, and doing justice to, complex data, and in order to achieve such understanding, the researcher needs ways of exploring complexity.' (Richards \& Morse 2007, p. 2).

This means that the qualitative researcher needs to be flexible and to adopt a critical, reflexive approach to the research process ${ }^{9}$. The methods of generating data can be adapted to changing 'real life' contexts, and to changes in the researcher's approach generated by the data. The integration of collection and analysis is seen in itself as a major strength of qualitative inquiry (Richards \& Morse 2007, p. 1). This unremitting adaptation of question, data and analysis means that each case is quite specific and is not reproducible. However, reproducibility is not necessary, as by the same token, qualitative research does not set out to produce predictive statements. The aim is to provide descriptions of and insights into specific cases, which may be informed by, and in turn inform, conceptualizations or theories. Descriptions produced in this way are sometimes described as 'thick', a term originally used by Ryle (1949), meaning that they incorporate considerable detail and depth. Although the outcomes of qualitative research may not be immediately transferable or predictive, if the

\footnotetext{
9 'Reflexivity in this sense means thinking critically about what you are doing and why, confronting and often challenging your own assumptions, and recognizing the extent to which your thoughts, actions and decisions shape how you research and what you see' (Mason, 2002a, p. 5).
} 
descriptions are sufficiently 'thick', others will be able to evaluate the extent to which the conclusions are transferable to different contexts.

\section{Complex data in cognitive neuroscience}

The cognitive sciences have always aimed at being able to make predictions about perceptual, emotional or cognitive processes that are valid in the real world. This proves particularly challenging in the case of dance, with its high degree of complexity, as well as the effects of liveness (no two performances are the same nor seen in the same context). Indeed, one may doubt whether it is possible at all to make consistent statements about the perceptual, emotional and cognitive processes associated with dance as seen from the phenomenological perspective.

In general, with advances in brain imaging technology it has been increasingly viable to relate brain activity with participants' individual, subjective evaluations and responses. Such an approach can add substantial information to the brain data and can be either predictive (e.g., effect of independent varied stimuli features on the dependent measures) or reversed (enhanced brain activity is traced back to the event in the stimuli). Calvo-Merino, Jola, Glaser and Haggard (2008) related the brain activity of naïve observers when watching dance movements to their consensus preference ratings. However, little attention has been paid to linking brain activity with individual experiential awareness in the field of movement observation. This may be partly due to technological limitations of fMRI. For instance, with EEG (Electroencephalogram) and TMS, functional processing can be identified in the human brain in the range of milliseconds whereas fMRI has a higher spatial (in the range of few millimeters) but lower temporal resolution (in the range of seconds). By means of TMS, researchers can trigger the motor cortex of a participant at a particular time-point and they will know exactly what the participant was shown in relation to the data measured. In fMRI, brain activity analysis is restricted to the time it takes to scan the brain areas of interest, which is usually around $1-3$ seconds. Therefore, if using more complex stimuli, several events are combined into one signal. In some studies, the participants' feedback is required to identify the underlying processes of the brain activity measured. This is for example the case in terms of research on consciousness where the participants' state of mind is the subject of investigation. 
One of the main topics is 'change blindness' (e.g. Simons \& Chabris, 1999; see also Simons \& Rensink, 2005), i.e., where the participant is not aware of what is in front of him. This raises interesting questions for phenomenological approaches, as the participants' description may not correspond to the actual stimulation. In our research, we are not questioning the spectators' reports, or that they 'miss out on one thing or another'. What the spectator experiences is what we want to know. This approach informed our neurophysiological design in the way we ignored - to a certain degree issues of stimulus complexity but instead focused on differences between audience members. This allowed us the freedom to not define a precise physical event to evaluate our measures of cortical excitability.

\section{The qualitative lens}

We have suggested that qualitative research can complement some of the limitations of neuroscience, and have indicated that our approach is informed by phenomenology. This means that we focus on dance spectatorship as lived, embodied experience, on which research participants are invited to actively reflect. Rather than being abstracted and decontextualised, the experience of watching dance is connected with the spectator's 'lifeworld'. 'Phenomenology attempts to explicate the meanings as we live them in our everyday existence, our lifeworld.' (Van Manen, 1990, p.11). To date, academic empirical research on Western theatre dance audiences is extremely rare, and existing research leans towards approaches informed by cognitive psychology rather than qualitative methods (Hanna, 1983; Glass, 2005; Glass \& Stevens, 2005). While a small but growing body of qualitative research on theatre audiences exists (Reason, 2010, 2006a, 2006b; Sauter, 2000; Schoenmakers, 1990), our approach is pioneering in the context of dance audiences. Our audience research activities take the form of interactions (usually but not always verbal), which take place after the performance, and therefore effectively deal with memories and reflections rather than with the experience of watching as it takes place in the moment. Reason writes, for instance, about his research with young audiences: 'in bringing participatory enquiry and phenomenology together one major objective was to invite the young audience members to reflect upon their experience and the construction of that experience through memory' (Reason, 2010, p. 133). 
To date, hermeneutical phenomenology has been the most influential strand in phenomenologically-informed audience research. Hermeneutical phenomenology emphasises the role of conscious reflection and also the use of language as part of lived experience (e.g. Van Manen 1990). Indeed, no experience can be accessed or communicated without some form of mediation. Van Manen states that because 'a person cannot reflect on lived experience while living through the experience', phenomenological reflection is therefore 'not introspective but retrospective'. Reflection on lived experience is always recollective; it is reflection on experience that is already passed or lived through.' (Van Manen 1990, p. 10). From this point of view, a spectator's 'experience' of the performance is not located solely in what takes place while they are watching, but encompasses re-construction and interpretation through subsequent reflection in social contexts, which can include activities such as interviews and focus groups. Rather than purely personal and private, experience is treated as socially mediated. Audiences are considered as active agents in constituting the meaning of the performance through articulating their experiences. In describing and discussing their responses to dance performances, the spectators we dialogue with have the opportunity to tease out what they themselves consider to be important about what they have seen. It is interesting to note that Glass found in her research on audiences of contemporary dance that experiences of dance, and also pre-performance information sessions, had relatively little impact on response, whereas audiences derived pleasure from post-performance discussions and enjoyed being asked their opinion and giving their interpretations of the work. This led her to hypothesize that 'Perhaps it is not pre-performance information that is important, but the observers' opportunity to reflect on their interpretation, understanding and connection with the piece' (Glass 2005, p. 120).

There is a strong tradition linking the study of dance and phenomenology (Sheets-Johnstone, 1980; Fraleigh, 1987). These earlier writings have been critiqued for their universalist approach to lived, embodied dance experience (e.g. Legrand \& Ravn, 2009), and Rothfield (2005) has argued for the need to extend the phenomenological approach to include corporeal specificity and to differentiate dance experience 'according to its social, historical and kinaesthetic milieux' (p. 44). She advocates a 'pluralization of the lived body' and argues that phenomenology should 'recast' the lived body as lived bodies. With its empirical base and its strong links 
with the social sciences, qualitative audience research is ideally placed to counter universalism. This can mean approaching interview data in a number of ways, diversifying the traditional phenomenological approach, by endeavouring to take account of factors such as race, gender, and cultural capital (as we have attempted to do in our study, detailed in the next section).

\section{Our duet}

\section{An approach to studying spectators' kinesthetic empathy using TMS and qualitative audience interviews}

Thus far we have outlined the interdisciplinary qualitative and quantitative approaches that are being employed in our research and indicated some of the broader methodological and epistemological issues of our collaboration. In this section, we illustrate ways in which we have attempted to link our disciplines by means of a study which combined methodologies of cognitive neuroscience and qualitative interviews informed by phenomenology.

For the study in question, volunteers watched three live solo performances: one short dance piece in the style of ballet, one in the style of bharatanatyam, and a non-dance acting performance (without voice) ${ }^{10}$. The aim of this study was to explore neuronal correlates of visual expertise in watching dance. Previous studies showed that the mirror neuron network is more strongly activated for actions that were shared between the observer and the performer, e.g., when expert dancers watched dance movements they were familiar with (Calvo-Merino, Glaser, Grèzes, Passingham, \& Haggard, 2005). This seminal study however did not differentiate between visual and motor experience or measure the spectators' response by any means other than the neuronal activity in the form of the BOLD (blood oxygenation level-dependent) signal. Following on subsequent studies (e.g. Calvo-Merino, Ehrenberg, Leung, \& Haggard, 2009) which explored visual and motor experience, our aim was to ascertain what, if any, was the impact of different degrees of viewing-only experience in each

\footnotetext{
${ }^{10} \mathrm{We}$ chose to compare the spectators' responses to watching ballet and bharatanatyam because these are discrete styles with well-defined vocabularies, by contrast with contemporary dance, which frequently combines elements of different styles. For a recording of each performance as staged in the TMS experiment please see http://paco.psy.gla.ac.uk/project.php?id=13.
} 
style on the viewers' neurophysiological response. This was evaluated by examining cortex excitability induced with TMS and by exploring data produced through qualitative audience research (see below). To separate visual from motor expertise, we only measured participants who had no physical dance training. Roughly a third of the participants were experienced spectators of ballet but not bharatanatyam, and a third were experienced spectators of bharatanatyam but not ballet, while the remainder had no experience in watching either. In order to measure effects of visual expertise in watching dance, it is important that the experiment corresponded as closely as possible to the 'normal' setting of the experience. Hence, the performers were professionals in each style, dressed in full costume, and danced a solo of 4.5 minutes to style-specific recorded music. This is an unconventional setting for both neursocientific experiments as well as qualitative audience research (see also section 4 , conclusions).

\section{The TMS experiment}

For the neuroscience research, we assessed cortical excitability as a sign of how much the audience is engaged with the performance. In general terms, the threshold for moto-corticospinal excitability is reduced when the subject is engaged with observing or executing a movement, e.g., during motor imagery, action observation, and motor preparation. ${ }^{11}$ In this experiment, participants' responses were measured while they were watching a live performance. The point of measure was clear and reproducible, but nonetheless movement selective. In other words, the participants' cortical excitability was measured every eight seconds with a random jitter of between zero and 2 seconds a total of 30 times. Hence, we ignored which particular type of movement the performer executed at each time point of the TMS trigger. This experiment was not designed to control systematically for particular

\footnotetext{
${ }^{11}$ Cortex excitability is indicated by the size of the amplitude of a motor evoked potential induced by single pulse transcranial magnetic stimulation (TMS, see Fadiga, L., Fogassi, L., Pavesi, G., \& Rizzolatti, G. (1995). Motor facilitation during action observation: A magnetic stimulation study. Journal of Neurophysiology, 73(6), 2608-2611). A number of magnetic stimulations were triggered over the participants' left motor cortex while they were watching the performance. The magnetic field induces an electric volley in the brain which evokes the neurons to send signals down the axons to move, in the form of action potentials comparable to when the participant would move voluntarily. This method is not invasive or painful. If the moto-corticospinal excitability is high, the amplitude of a TMS induced motor evoked potential on the right hand or arm contralateral to the site of the stimulation is larger, and vice versa.
} 
movements within each style. Since we do know that our individuals were different in their visual experience and they would experience individual levels of enjoyment, we focused on correlating their subjective responses with differences in neurophysiological data.

The experiment showed that the excitability of the cortex of spectators who have previous visual experience in watching ballet is higher when they watch ballet than any of other performance forms, with which they were less familiar. This was not the case for either the control group or the experienced bharatanatyam spectators (whose level of experience was less consistent). ${ }^{12} \mathrm{We}$ also found significant correlations between the participants' levels of empathic abilities and their response to watching dance: participants who scored higher on empathy ${ }^{13}$ showed higher cortical excitability than those who scored low (Jola, Kuppuswamy, Grosbras, \& Pollick, submitted). However, these results were based on comparing the responses to the different styles by different groups of participants (those who scored high or low on empathy, those who were visually experienced or inexperienced spectators of ballet or bharatanatyam, or novices in both forms). No conclusions were made about individual subject's experiences. So-called case studies could be pursued (i.e., Kosslyn et al., 2002) but we have yet to define valid scientific selection criteria to single out individuals as case studies from the 32 participants.

\section{The qualitative interviews}

For the audience research, each subject participated (after watching the performances) in a semi-structured interview i.e. an interview which uses certain preset questions, but where the order can be varied and the interviewer can also respond to directions suggested by the interlocutor's response (see Mason 2002b). We did not want to be confined by our own questions, which would inevitably influence interviewees' responses. The emphasis was on encouraging participants to describe freely what they had seen or felt and their responses to it. However, the interviews were themed around certain questions, such as identifying parts of the performance

\footnotetext{
${ }^{12}$ Owing to the difficulty of recruiting experienced bharatanatyam spectators in Glasgow, these spectators were less experienced than the ballet spectators.

${ }^{13}$ We used the Interpersonal Reactivity Index by Davis, M. H. (1980). Multidimensional Approach to Individual Differences in Empathy. JSAS Catalog of Selected Documents in Psychology, 10, 85.
} 
they particularly liked. The number of themes and responses were rich and complex, as one would hope and expect in qualitative research. Some participants said that they felt they were responding in their face to the facial expression of the dancer. In one exchange, ${ }^{14}$ the participant reported that her response was focused on the bharatanatyam dancer's smile and that she also valued the physical closeness to the dancer which resulted from the small performance space, as opposed to the less intimate environment of a theatre. So from asking about embodied response we also learned about what made the bharatanatyam dance performance enjoyable for her and made her feel involved. For the ballet (for which she was an experienced spectator, and described herself as 'a classical ballet fan') her response was quite different. Here she was judging according to criteria with which she was familiar, and many of her comments were evaluations of whether the dancer lived up to her expectations of what ballet should be: 'Well pirou...pirouettes and her point, her footwork was excellent, her positioning of her hands and arms were, um, spot on'. In addition to positive aesthetic judgments, watching the ballet made this participant feel emotional and also made her feel that she wanted to dance herself.

We used the software package NVivo to devise categories ('nodes') to facilitate qualitative interview analysis, starting off with nodes which were anticipated through our research questions such as 'familiarity' and 'unfamiliarity', 'connection to dancer', 'desire to move', 'embodied response'. However, close reading of the interview material also prompted us to add new categories, such as 'admiration of virtuosity', 'evaluation of quality' and even 'can't remember'. The latter was because lack of familiarity or understanding sometimes made it difficult for participants to take in or remember much of what they had seen. Another category that we added was

\footnotetext{
${ }^{14}$ Interviewer: Mm and would you say, if, um, this is a rather unusual question but, um, could you identify any particular er, part of your body that you felt you responded to, um, particularly, like, um, was it in your...

Nathalie: My face probably.

Interviewer: Right, so you felt you were responding in your face?

Nathalie: Yeah.

Interviewer: Right, right.

Nathalie: I was responding to the way she was smiling and the way she was looking, her eyes, I would say, probably more facial for me as well rather than anything else.

Interviewer: Responding in what way?

Nathalie: Because of the smile. She made you want to smile, she made you interested in what she was doing, um, which I thought was very nice and it's not often you get the chance to see someone as close as that, dancing. Normally they're on the, in the gallery, you know, in the, obviously in the theatre and you just don't have that close response.
} 
'motivation' as it became evident that what the participants were looking for in a dance performance had a huge effect on how they responded to what they saw. This impacted on our understanding of the original research questions.

\section{Spectators' enhanced excitability}

Whereas we had started out to explore the importance of familiarity in terms of viewing experience, people's responses underlined for us the importance of wider factors relating to cultural competence, as described by Bourdieu. 'A work of art has meaning and interest only for someone who possesses the cultural competence, that is, the code, into which it is encoded. [...] A beholder who lacks the specific code feels lost in a chaos of sounds and rhythms, colours and lines, without rhyme or reason.' (1984, p. 3). By the same token, an individual's general disposition to consume and seek exposure to certain kinds of things is not random or even necessarily wholly selfaware but instead deeply ingrained into embodied cultural practices and their associated social and economic conditions (see Reason \& Reynolds, 2010, forthcoming). While the audience research provided examples which corroborated the TMS findings about the effects of visual expertise on movement simulation, it also brought into play factors of cultural experience and motivations, as it was not only what the participants had seen of a given dance style (their level of viewing experience), but also their preconceived/culturally received ideas about it and their personal preferences or motivations which affected how they experienced it. ${ }^{15}$

\section{Matching different ways of representing kinesthetic empathy}

Our question in this next part of the research was: what is the correspondence between the data from the neuroscience research for each individual's average responses to the three performances and their verbal experiences in the interviews? In

\footnotetext{
${ }^{15}$ This complements previous studies in cognitive neuroscience. For instance, Molnar-Szakacs, Wu, and Iacoboni (Molnar-Szakacs, I., Wu, A. D., Robles, F. J., \& Iacoboni, M. (2007). Do you see what I mean? Corticospinal excitability during observation of culture-specific gestures. PLoS One, 2 (7), e626) found that motor cortex excitability of the spectator is enhanced when they observed culturally coded hand gestures performed by an actor of their own linguistic, regional or cultural community. However, their study was about the effects of cultural learning on social communication in everyday situations, and did not relate cortical excitability to personal preference. As indicated by qualitative audience research as well as neuroscientific data, our study showed enhanced cortical excitability when the observed movements matched the spectators' expectations and aesthetic appreciations.
} 
particular, we were interested to find out whether stronger responses as measured through TMS corresponded to stronger kinesthetic responses and/or levels of enjoyment as articulated through interviews. If we were to find participants' experiences reflected in their neurophysiological responses, would the explanatory gap between cognitive neuroscience and qualitative audience research be narrowed? However, while attempting to match individual verbal reports with individual cortical excitability, we reminded ourselves that this is not much different from the psychological phenomenon of pareidolia, i.e., seeing a random stimulus as being significant, as it often is described by the example of seeing figures in the clouds. How can we see the connection between the data gathered without over-interpreting? The human perceptual system acts in a creative manner (see section 2 above), so if we wanted to identify a subject's verbal report in the neurophysiological data, we could find some connections, without them 'actually being there'. The only way to reduce any bias, from a neuroscientific perspective, would be a 'blind review' in form of a researcher who was kept uninformed about the studies' aims.

Hence, similar to an inter-rater reliability test, a former student who had no experience with this study was paid to match both types of data, i.e., cortical excitability with verbal reports. First, she was asked to find the neurophysiological responses to each performance that belong to the same individual ${ }^{16}$. Clearly, these data were from the same individual, and should therefore be related, however, if the movements between hand and arm were different at any time point of the randomly applied triggers between the three types of performances observed, the data could not only be matched according to their overall level (such as when high empathic abilities give higher cortex excitability independent of the movement observed). Second, the student was asked to select a few salient audience research transcripts and find the corresponding data. However, as expected, her task was a very difficult one, if not impossible: of all participants, the cortical excitability of the hand and arm were matched correctly for one participant only. This means that she was not able to identify one person's data, i.e., matching graphs of the hand (as measured during the bharatanatyam performance) to the arm (as measured during the ballet performance). This is not surprising, as the location of the measure, the embodiment, varied between

\footnotetext{
${ }^{16}$ We measured motor evoked responses in the finger and the arm, and therefore, each subject had two averaged graphs, one for the finger, one for the arm, with values for each performance type.
} 
different types of performances (in ballet, expressive gestures emphasize arm movements, while in bharatanatyam they emphasize finger movements). Interestingly, of the incorrectly matched data, the student matched 6 out of 11 ballet spectators with other ballet spectators, 3 out of 10 novices, and none out of 8 experienced bharatanatyam spectators. It seems thus that the student's naïve matching corresponds with the scientific observation, namely, that the responses of the bharatanatyam spectators were the most inconsistent ones. As noted above, the ballet spectators were more experienced than the bharatanatyam spectators. Hence, the objective raters' outcome supported the information we gained for the qualitative audience research.

\section{Conclusions: Situating Experience across Disciplines}

"All my knowledge of the world, even my scientific knowledge, is gained from my own particular point of view, or from some experience of the world without which the symbols of science would be meaningless" (Merleau-Ponty, 1945, p. ix).

In this paper, we have mapped parts of our experiences to date in combining epistemologically and methodologically contrasting approaches in our exploration of spectators' responses to watching dance. This process requires openness to each researcher's position at the same time as being grounded in our own disciplines, combining the readiness and skill to perform 'grand jetés' across disciplinary boundaries with core strength and balance.

Generally, neuroscience works within a paradigm which values precision and statistically significant results that should be valid for a wider population. Phenomenologically based audience research values more open-ended exploration and rich data situated culturally, historically, and/or socially. This contrast could make neuroscience seem conclusive and fixed, though we have found that this is not always the case, and we value Merleau-Ponty's statement, cited above, which acknowledges the grounding of all knowledge in lived experience.

Our aim is to evolve working practices which enable us to relate to each other's disciplines while retaining the distinct properties of each. A particular challenge here is the role of institutional contexts where discipline-specific, peer-reviewed research is viewed as the optimum output and is generally valued more highly than other forms 
of knowledge transfer and exchange, such as open-ended discussions. Such interactions are crucial to the success of innovative, collaborative research and demand substantial investment of time and resources. However, shared activities such as writing a paper like this have helped us face head-on epistemological assumptions which would have remained implicit if we had limited ourselves to contributing to discipline-specific journals.

We have attempted to let neither neuroscience nor audience research methodology take primacy over the other but to work bi-directionally. We have thus adopted an interactive approach, seeking to gain insights into the other's methodologies and exploring ways of involving them and their results in our own discipline. For instance, the questionnaire used to correlate empathy scores with cortex excitability in cognitive neuroscience highlighted that the qualitative research does not use such a tool, but the results have informed qualitative discussions of how kinesthetic response relates to empathy. The qualitative researchers have also introduced a quantitative aspect to their research by developing a questionnaire in conversation with the neuroscientists aimed to further understanding of audiences' motivations, which will be posted online and distributed at theatres, and will be analysed quantitatively. In the other direction, it emerged through the interviews that there were significant differences in the extent to which audience members focused on certain parts of the body, e.g. legs and feet/arms and upper body. Exploring the reasons for this is likely to prove a fruitful area of investigation for cognitive neuroscience.

We are learning to value contrasting aspects of each other's fields, and to challenge fixed conceptions. Rather than eliminating disciplinary differences, we aim to advance knowledge and understanding of the other position (e.g. through reading each other's work, reading material across disciplines, and even training in aspects of each other's research methodologies). Flexibility on both sides is required to achieve these aims, including challenging our methodological approaches by considering new ways of thinking via collaboration (Moran, 2010, p. 181). For instance, the dance performances for the TMS experiments and qualitative interviews stretched the parameters of the TMS procedures in the direction of empirical neuroscience stimuli, but also required acceptance of deviation from 'normal' theatre conditions for the 
audience researchers. There may be the risk here of compromising at both ends and thus being open to critique from within our chosen disciplines about the rigour of our methods. However, without this flexibility we would not be able to communicate across different disciplinary approaches.

Our interchanges encompass tensions and moments of noncontact/comprehension, but the research would not be possible without the singular and the collaborative contributions. We hope that sharing some of the challenges and benefits that we have faced in this project may be of value to other researchers who choose to adopt an interdisciplinary strategy. 
The research underpinning this paper was carried out under the aegis of the "Watching Dance: Kinesthetic Empathy' project, which is funded by the Arts and Humanities Research Council. The authors would like to acknowledge the other members of the Watching Dance project team: Prof. Frank Pollick, Dr. Marie-Hélène Grosbras, Dr. Matthew Reason, Dr. Anna Kuppuswamy and Karen Wood, MSc. We would also like to thank Scottish Ballet, the dancers and participants in our studies thus far. 


\section{BIBLIOGRAPHY}

Aglioti, S. M., Cesari, P., Romani, M., \& Urgesi, C. (2008). Action anticipation and motor resonance in elite basketball players. Nature Neuroscience, 11(9), 1109 - 1116.

Baron-Cohen, S., \& Wheelwright, S. (2004). The empathy quotient: an investigation of adults with Asperger syndrome or high functioning autism, and normal sex differences. Journal of Autism and Developmental Disorders, 34(2), 163 - 175.

Bourdieu, P. (1984). Distinction: a social critique of the judgement of taste. London: Routledge.

Brown, S., Martinez, M. J., \& Parsons, L. M. (2006). The neural basis of human dance. Cerebral Cortex, 16(8), 1157 - 1167.

Calvo-Merino, B., Ehrenberg, S., Leung, D., \& Haggard, P. (2009). Experts see it all: configural effects in action observation. Psychological Research, 74(4), 400 - 406.

Calvo-Merino, B., Glaser, D. E., Grèzes, J., Passingham, R. E., \& Haggard, P. (2005). Action observation and acquired motor skills: an fMRI study with expert dancers. Cerebral Cortex, 15(8), 1243 - 1249.

Calvo-Merino, B., Grèzes, J., Glaser, D. E., Passingham, R. E., \& Haggard, P. (2006). Seeing or Doing? Influence of visual and motor familiarity in action observation. Current Biology, 16(19), 1905 - 1910.

Calvo-Merino, B., Jola, C., Glaser, D. E., \& Haggard, P. (2008). Towards a sensorimotor aesthetics of performing art. Consciousness and Cognition, 17(3), 911 - 922.

Cross, E. S., Hamilton, A. F., \& Grafton, S. T. (2006). Building a motor simulation de novo: observation of dance by dancers. Neuroimage, 31(3), 1257 - 1267.

Cook, L. A., \& Van Valkenburg, D. L. (2009). Audio-visual organisation and the temporal ventriloquism effect between grouped sequences: evidence that unimodal grouping precedes cross-modal integration. Perception, 38(8), 1220 - 1233.

Daly, A. (1992). Dance history and feminist theory: Reconsidering Isadora Duncan and the male gaze. In L. Senelick (ed). Gender in Performance: The Presentation of Difference in the Performing Arts, Tufts University/University Press of New England: Hanover.

Dehaene, S. (1989). Discriminability and dimensionality effects in visual search for featural conjunctions: a functional pop-out. Perception \& Psychophysics, 46(1), 72-80.

Fechner, G. T. (2009). Uber den Tanz. In Gutenberg-DE, Das Literaturarchiv (Vol. ed. 11): Hille \& Partner GbR.

Foster, S. (2008). Movement's Contagion: The Kinesthetic Impact of Performance. In Davis, Tracy C. (Ed) The Cambridge Companion to Performance Studies (pp. 46 - 59). Cambridge: Cambridge University Press.

Fraleigh, S. H. (1987). Dance and the lived body: A descriptive aesthetics. Pittsburgh: University of Pittsburgh Press.

Friesen, J. (1975). Perceiving Dance. Journal of Aesthetic Education, 9(4), 97 - 108.

Gallagher, S. \& Zahavi, D. (2008). The phenomenological mind: an introduction to philosophy of mind and cognitive science. London and New York: Routledge.

Gallese, V., Fadiga, L., Fogassi, L., \& Rozzolatti, G. (1996). Action recognition in the premotor cortex. Brain, 119(Pt 2), 593 - 609.

Glass, R. (2005). Observer response to contemporary dance. In R, Grove, C. Stevens and S. McKechnie (Eds.), Thinking in four dimensions: creativity and cognition in contemporary dance (pp. 107 - 121). Melbourne: Melbourne University Press.

Glass, R., \& Stevens, C. (2005). Making sense of contemporary dance: an australian investigation into audience interpretation and enjoyment levels. Sydney: University of Sydney.

Hagendoorn, I. (2004). Some speculative hypotheses about the nature and perception of dance and choreography. Journal of Consciousness Studies, 11(3-4), 79 - 110.

Hanna, J. L. (1983). The Performer-Audience Connection: Emotion to Metaphor in Dance 
and Society. Austin: University of Texas Press.

Hasson, U., Nir, Y., Levy, I., Fuhrmann, G., \& Malach, R. (2004). Intersubject synchronization of cortical activity during natural vision. Science, 303(5664), $1634-1640$.

Hasson, U., Yang, E., Vallines, I., Heeger, D. J., \& Rubin, N. (2008). A hierarchy of temporal receptive windows in human cortex. Journal of Neuroscience, 28(10), 2539 - 2550.

Jola, C., Kuppuswamy, A., Pollick, F., \& Grosbras, M. H. (submitted). Enhanced cortical excitability induced by watching dance in empathic and visually experienced dance spectators.

Jola, C., \& Mast, F. (2005a). Mental object rotation and egocentric body transformation: two dissociable processes? Spatial Cognition and Computation, 5(2\&3), 217 - 237.

Jola, C., \& Mast, F. W. (2005b). Dance Images. Mental imagery processes in dance. In J. Birringer \& J. Fenger (Eds.), Tanz im Kopf. Dance and cognition (Vol. 15, pp. 211 232). Münster: LIT Verlag

Keysers, Chr., \& Gazzola, V. (2009). Expanding the mirror: vicarious activity for actions, emotions, and sensations. Current Opinion in Neurobiology, 19(6), 666 - 671.

Kosslyn, S. M., Cacioppo, J. T., Davidson, R. J., Hughdahl, K., Lovallo, W. R., Spiegel, D., et al. (2002). Bridging psychology and biology. The analysis of individuals in groups. American Psychologist, 57(May, 5), 341 - 351.

Legrand, D., \& Ravn, S. (2009). Perceiving subjectivity in bodily movement: The case of dancers. Phenomenology and Cognitive Science, 8, 389 - 408.

Lipps, T. (1906). Asthetik: Psychologie des Schönen und der Kunst (Vol. 2ndr). Hamburg: Leopold Voss.

Martin, J. (1939). Introduction to the dance. New York: Dance Horizons.

MacFarlane, L., Kulka, I., \& Pollick, F. E. (2004). The representation of affect revealed by butoh dance. Psychologia - An International Journal of Psychology in the Orient. SI: Nonverbal Communication and Action Recognition, 47(2), 96 - 103.

Mason, J. (2002a). Qualitative researching (2nd ed.). London; Thousand Oaks, Calif.: Sage Publications.

Mason, J. (2002b). Qualitative Interviewing: Asking, Listening and Interpreting. In T. May (Ed.), Qualitative Research in Action (pp. 225 - 241). London: Sage.

Merleau-Ponty, M. (1945). Phenomenology of perception (C. Smith, Trans.). London and New York: Routledge.

Mishara, A. L. (2007). Missing links in phenomenological clinical neuroscience: why we still are not there yet. Current Opinion in Psychiatry, 20, 559 - 569.

Moran, J. (2010). Interdisciplinarity (New Critical Idiom). $2^{\text {nd }}$ edition, New York: Routledge.

Munzert, J., Zentgraf, K., Stark, R. \& Vaitl, D. (2008). Neural activation in cognitive motor processes: comparing motor imagery and observation of gymnastic movements. Experimental Brain Research, 188, 437 - 444.

Pollick, F., Jola, C., Petrini, K., McKay, L., McAleer, P., \& Simmons, D. (2010, forthcoming). Experience and the perception of biological motion. In K. Johnson \& M. Shiffrar (Eds.), Perception of the human body in motion: Findings, theory, and practice. Oxford: Oxford University Press.

Reason, M. (2010, forthcoming) Asking the Audience: Audience Research and the Experience of Theatre. In Gay McAuley and Laura Ginters (Eds.), special Issue, Audiencing: the Work of the Spectator in Live Performance, About Performance, 10.

Reason, M. (2010) The Young Audience: Exploring and Enhancing Children's Experiences of Theatre. Stoke on Trent: Trentham.

Reason, M. (2006a). Young audiences and live theatre, Part 1: Methods, participation and memory in audience research. Studies in Theatre and Performance, 26(2), 129-145.

Reason, M. (2006b). Young audiences and live theatre, Part 2: Perceptions of Liveness in Performance'. Studies in Theatre and Performance, 26(3), 221 - 241.

Reason, M. and Reynolds, D. (2010, forthcoming) Kinesthesia, Empathy and Related Pleasures: An Inquiry into Audience Experiences of Watching Dance Dance Research Journal, 42(2), Winter 2010. 
Richards, L., \& Morse, J. M. (2007). Read me first for a User's Guide to qualitative methods. London: Sage.

Rothfield, P. (2005). Differentiating phenomenology and dance. Topoi, 24, 43 - 53.

Ryle, G. (1949). The Concept of Mind. London: Hutchinson.

Treisman, A., \& Gelade, G. (1980). A feature-integration theory of attention. Cognitive Psychology, 12, 97 - 136.

Sauter, W. (2000). The theatrical event: dynamics of performance and perception. lowa City: University of lowa Press.

Schoenmakers, H. (1990). The spectator in the leading role: developments in reception and audience research within Theatre Studies. In W. Sauter (Ed.), New directions in theatre research. Munksgaard: Nordic Theatre Studies.

Sherrington, C. S. (1907). On the proprio-ceptive system, especially in its reflex aspect. Brain, 29, 467 - 485.

Sheets-Johnstone, M. (1980). The phenomenology of dance. London: Dance Books.

Simons, D. J., \& Chabris, Chr. F. (1999). Gorillas in our midst: sustained inattentional blindness for dynamic events. Perception, 28, 1059 - 1074.

Simons, D. J., \& Rensink, R. A., Change blindness: past, present, and future. Trends in Cognitive Sciences, 9(1), 16 - 20.

Spillmann, L. (1999). From elements to perception: Local and global processing in visual neurons. Perception, 28, 1461 - 1492.

Spillmann, L. (2009). Phenomenology and neurophysiological correlations: Two approaches to perception research. Vision Research, 49, 1507 - 1521.

Van Manen, H. (1990). Researching lived experience: human science for an action sensitive pedagogy. London, Ontario: Althouse.

Wade, N. J., \& Bruce, V. (2001). Surveying the seen: 100 years of British vision. British Journal of Psychology, 92, $79-112$.

Wade, N. J. (2003). The search for a sixth sense: the cases for vestibular, muscle, and temperature senses. Journal of History of the Neurosciences, 12(2), $175-202$.

Zeki, S. (2002). Neural concept formation and art: Dante, Michelangelo, Wagner. Journal of Consciousness Studies, 9(3), 53 - 76. 


\section{FIGURE CAPTIONS}

Figure 1. Examples of experimental stimuli used in scientific research from pop-out feature detection to motion perception, and a scene from a piece that an audience may see (from top left clockwise). Figures by Austin Mcwiggin (feature integration, wikipedia project), Corinne Jola (point-light display), Scottish Ballet (Gregory Dean as the French Prince, Jarkko Lehmus as The King, Eve Mutso as The Queen, Tama Barry as the Russian Prince and Christopher Harrison as the Austrian Prince in Page's The Sleeping Beauty. Photograph by Andrew Ross). 
FIGURES
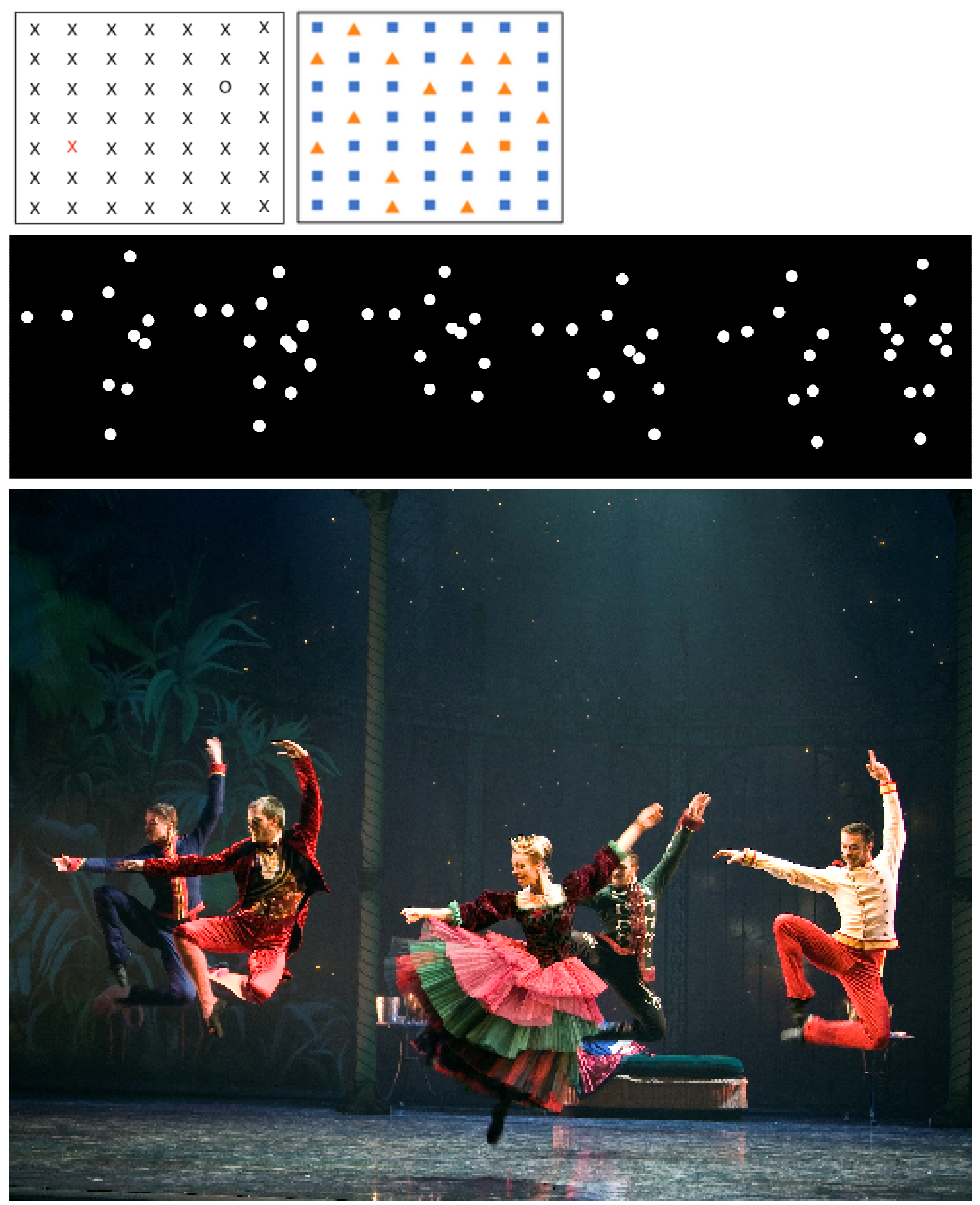